This is a post-print of:

Thorburn, R., Bowman-Smith, C. K., \& Friedman, O. (2020). Likely stories: Young children favor typical over atypical story events. Cognitive Development, 56, 100950. https://doi.org/10.1016/j.cogdev.2020.100950

*This document may not correspond perfectly with the published article*

\title{
Likely stories: Young children favor typical over atypical story events
}

\author{
Rachel Thorburn, Celina K. Bowman-Smith, and Ori Friedman \\ Department of Psychology, University of Waterloo
}

\begin{abstract}
Author Note
Rachel Thorburn, University of Waterloo; Celina K. Bowman-Smith, University of Waterloo; Ori Friedman, University of Waterloo.

Research was supported by a grant from the Natural Sciences and Engineering Research Council of Canada awarded to OF. We are grateful to Deena Weisberg for her many helpful suggestions on this work.

Correspondence concerning this article should be addressed to Ori Friedman, Department of

Psychology, University of Waterloo, 200 University Avenue W, Waterloo, Ontario, Canada N2L

3G1. E-mail:friedman@uwaterloo.ca
\end{abstract}




\begin{abstract}
Across four experiments (total $\mathrm{N}=280$ ) we find that children aged 2-4 show a novel bias favoring typical over atypical story events. In Experiment 1, 2-3-year-olds expected animals in a story to eat species-typical foods, even though other animals in the story ate foods atypical for their species. In Experiment 2, 2-3-year-olds successfully remembered atypical events in a story, which suggests the bias does not result from difficulty remembering these events. In Experiment 3, 3-4-year-olds chose atypical events when judging how a story would continue. But when predicting how the experimenter would continue the story, they were as likely to choose typical events. In Experiments $4 A \& B$, children persisted in choosing typical events after having been asked to explain why earlier story events had been atypical. Overall, our findings suggest that children favor typical over atypical story events and may have difficulty disregarding or overriding the bias.
\end{abstract}

Keywords: typicality; stories, fiction; knowledge 


\section{Likely Stories: Young Children Favor Typical Over Atypical Story Events}

When deciding what happens in a story, young children often choose realistic events over fantastic ones (Kibbe et al., 2018; Sobel \& Weisberg, 2014; also see Weisberg \& Sobel, 2012). For example, 4-year-olds judge that a story character who can fly and turn invisible will walk to a store rather than appearing there magically (Weisberg et al., 2013). Likewise, when completing a story about a character who attends dragon-taming school, 4-6-year-olds are as likely to say the character will ride a regular school bus as one with wings (Kibbe et al., 2018). Adults, in contrast, mostly choose fantastic events for fantastic stories (Weisberg et al., 2013).

Children's might choose realistic and mundane story events because they are realityprone when thinking about stories (Weisberg et al., 2013). For example, in the story about visiting a store, children may favor walking because it is possible, and they may disdain teleporting because it is impossible and violates the laws of physics. A childhood "reality" bias for stories may be surprising because fantastic content is common in the books, movies, and television shows that children consume and enjoy. For example, one study found supernatural content in $92 \%$ of popular media developed for children (Goldstein \& Alperson, 2019). Children's bias to choose realistic events for stories may also be surprising because they understand how stories differ from reality. Even preschoolers understand that story characters are not real and that fantastical events in storybooks and cartoons could not really happen (e.g., Corriveau et al., Kim et al., 2009; Li et al., Boguszweski \& Lillard, 2015; Woolley \& Cox, 2007; see Weisberg, 2013 for a review). Nonetheless, a childhood reality bias is consistent with findings that young children's imaginations are constrained by their knowledge of realitychildren sometimes report being unable to imagine impossible events (Lane et al., 2016). The bias also fits with findings suggesting that young children expect fictions enacted in pretend play 
to be realistic - young children use their real-world knowledge to interpret and continue pretense scenarios (e.g., Kavanaugh \& Harris, 1994; Leslie, 1994), and sometimes protest and correct unrealistic pretense that conflicts with this knowledge (Van de Vondervoort \& Friedman, 2017).

Children's choices of realistic story events could also stem from a different bias. Children might be drawn to events that fit with their knowledge of what is typically and normally true. On this account, children favor walking because it is a typical way of going elsewhere, whereas teleporting is not. This proposal fits with findings that typicality and regularity are important in children's thinking. They often deny that atypical or abnormal events could happen in real life. For example, 4-8-year-olds often deny that a person could drink onion juice or find an alligator under their bed, even though these events are actually possible (Shtulman \& Carey, 2007; also see Bowman-Smith et al., 2019; Goulding \& Friedman, in press; Lane et al., 2016; Lane et al, 2018; Shtulman 2009; Shtulman \& Phillips, 2018; Sobel \& Weisberg, 2014). Similarly, young children often deny that atypical members of a category are in fact members of the category. For example, they deny that an island is really an island if it has apartment buildings and snow on it, rather than coconut and palm trees (Keil \& Batterman, 1984).

In this paper, we investigate whether children show a typicality bias when thinking about stories. As we saw in the story about going to the store, the typicality bias and reality bias will sometimes lead children to the same response. In that story, both biases favored walking (typical and possible) over teleporting (atypical and impossible). Although previous findings are consistent with children showing a typicality bias for stories, we know of no evidence that specifically supports this bias. To provide such evidence, we told children stories where the typicality bias leads to a distinctive response pattern. Consider a story where a rabbit can eat celery or a carrot. The typicality bias should lead children to judge that the rabbit will eat the 
carrot (i.e., rabbits typically eat carrots). In contrast, both food choices fit the reality bias as neither is impossible or fantastic. ${ }^{1}$

We conducted four experiments. The first experiment provides evidence that children do show the typicality bias. The next experiments then attempt to investigate whether the bias stems from limits in young children's processing abilities. Children could have difficulty remembering atypical story events, or they could fail to generalize about such events. Either difficulty would leave children with little reason to anticipate that a story with many atypical events should include further ones. One previous finding may speak against these processing accounts. Weisberg et al. (2013) included a word-learning condition where children were shown several fantastic pictures and told that each of them was "daxy". When asked to identify other "daxy" pictures, children chose fantastic over realistic pictures, which suggests they can remember and generalize about atypical items. However, children were instructed at the outset to learn the meaning of the novel word, and this may have prompted them to look for patterns where they normally would not. Also, in this condition, the pictures were not presented as part of a story. We felt that children's ability to remember and generalize about atypical story events warrants further study.

\section{Experiment 1}

We told children a story where animals ate foods atypical for their species, rather than species-typical foods. For example, a squirrel ate a pear instead of a nut. Children then judged whether further animals in the story would eat typical or atypical foods. If children show the

\footnotetext{
${ }^{1}$ The typicality and reality biases are not mutually exclusive; children may be subject to both biases. So evidence that children show the typicality bias does not undermine claims that children show the reality bias in other circumstances.
} 
typicality bias, they should disregard the pattern of animals eating species-atypical foods, and instead predict that the animals will eat foods typical for their species.

The children we tested were aged 2 and 3 years, the youngest ages we thought capable of completing the task. Some earlier work on the reality bias suggested that children at these ages might not show the typicality bias. Although the reality bias was observed in children aged 4 years and older, it was not found in 3-year-olds (Sobel \& Weisberg, 2014). They chose fantastic events as often as realistic events for a story, regardless of whether the protagonist was an ordinary human or was an alien from the planet Zolnar. This finding is relevant to the typicality bias because besides being impossible, the fantastic events were also atypical. We anticipated, though, that younger children might show the typicality bias if tested with a sufficiently simple procedure.

\section{Methods}

Participants. We tested 812 - and 3-year-olds $(M=3 ; 0$ [years;months], range $=2 ; 0-3 ; 11$, 44 males). Three other children were tested but excluded because they did not respond to any test questions. We aimed to test 20 children per age (in years) per between-subject condition, and to randomly assign equal numbers of children at each age to each condition. However, we tested one additional child. This recruitment goal corresponded with our lab stopping rule when this research was initiated (though the rule was later adjusted). Regardless, other work (from our lab and others) shows that testing 40 children per between-subject condition can reveal main effects alongside interactions with age. In all experiments, children were recruited from and tested at daycares, preschools, and elementary schools in the Waterloo Region (Ontario, Canada). Residents of the region are predominantly middle-class; $81 \%$ of residents are White, and Chinese and South Asians residents are the main visible minority. 
Materials and procedure. In all experiments, children were shown visual stimuli on a laptop computer with accompanying narration and questions by the experimenter; see Table 1 for sample story items and test questions from each experiment, and the Supplemental Materials for the complete testing scripts.

Children first saw a picture of five animals (monkey, squirrel, dog, mouse, rabbit), and were told the animals were hungry. Children then watched two scenarios in which animals found and ate food. In each scenario, an animal appeared with two foods - one typically eaten by members of its species, and another food atypical for its species. In the first scenario, a monkey appeared with a banana and an apple, and in the second scenario, a squirrel appeared with a nut and a pear. In one between-subjects condition, each animal ate the species-typical food. In another between-subjects condition, each animal ate the species-atypical food.

Children then completed three test trials. In each trial, one of the three remaining animals appeared with a species-typical food and an atypical food (dog with bone and pizza; mouse with cheese and pineapple; rabbit with carrot and celery), and children were asked what the animal would eat (e.g., "Here's a pineapple and some cheese. Look! Here comes a mouse. What will the mouse eat?")

We anticipated that children who first saw animals eat typical foods (e.g., squirrel eating nut) would go on to say that the animals in the test trials would also eat typical foods. Our main interest, though, was whether children who saw animals eat atypical foods (e.g., squirrel eating pear) would show the typicality bias and choose foods typical to each species, or instead respond by continuing the pattern by choosing foods atypical for each species. 


\section{Table 1}

Sample Stories and Test Questions From Each Experiment

\begin{tabular}{lll}
\hline Experiment & Sample story & Sample test question \\
\hline 1 & $\begin{array}{l}\text { Here's an apple and a banana, here comes a monkey } \\
\text { and it eats the apple/banana. }\end{array}$ & $\begin{array}{l}\text { Here's some pizza and a bone, and look here comes a } \\
\text { dog. What will the dog eat? }\end{array}$ \\
& $\begin{array}{l}\text { Here's Morty the monkey/Billy the Goat. Morty/Billy } \\
\text { is very hungry, and look here's some food he can eat! } \\
\text { Here's an apple and a banana. Morty/Billy decides to }\end{array}$ & $\begin{array}{l}\text { Look here's Morty/Billy again! Do you remember } \\
\text { which food Morty/Billy ate? }\end{array}$ \\
& $\begin{array}{l}\text { eat the apple. So which food did Morty/Billy eat? } \\
\text { Here's Morty the monkey. Morty is very hungry, and } \\
\text { look here's some food he can eat! Here's an apple and } \\
\text { a banana. Morty decides to eat the apple. }\end{array}$ & $\begin{array}{l}\text { Here's Daisy the dog. Daisy is very hungry, and look } \\
\text { here's some food she can eat. Here's a bone and some } \\
\text { peas. Daisy decides to eat a food. So what food will I } \\
\text { say/Daisy eat? }\end{array}$ \\
& $\begin{array}{l}\text { Here's Morty the monkey. Morty is very hungry, and } \\
\text { look here's some food he can eat! Here's an apple and } \\
\text { a banana. Morty decides to eat the apple. Do monkeys }\end{array}$ & $\begin{array}{l}\text { Here's Daisy the dog. Daisy is very hungry, and look } \\
\text { here's some food she can eat. Here's a bone and some } \\
\text { peas. Which food will Daisy eat? }\end{array}$ \\
& $\begin{array}{l}\text { usually eat apples? Why/How do you think Morty ate } \\
\text { the apple? }\end{array}$ & \\
\hline
\end{tabular}

Note. Highlights shows text differing across between-subjects condition.

\section{Results and Discussion}

In all experiments, we analyzed children's responses using generalized estimating equations (GEE) models (binary logistic). Each model included a two-level between-subjects factor and age-in-months (mean-centered and entered as a continuous predictor variable). The complete data from all experiments are available online at osf.io/qn5ak/.

Figure 1 (first panel) shows the proportion of trials in which children judged that animals would eat atypical foods. The GEE model revealed no main effect of condition (typical, atypical), Wald $\chi^{2}(1)=0.55, p=.459$, no main effect of age, Wald $\chi^{2}(1)=2.74, p=.098$, and no interaction, Wald $\chi^{2}(1)=1.32, p=.251$. A one-sample test revealed that children mostly chose typical foods, rather than atypical ones, Wald $\chi^{2}(1)=75.26, p<.001$. In sum, children in both conditions rarely indicated that the animals would eat atypical foods, and instead mostly chose the typical foods. ${ }^{2}$

\footnotetext{
${ }^{2}$ Children in Experiments 4A \&4B acknowledged that the food choices in the opening scenarios were atypical, ruling out the possibility that children did not know what the animals in the opening scenarios typically eat. These children also went on to show the typicality bias.
} 


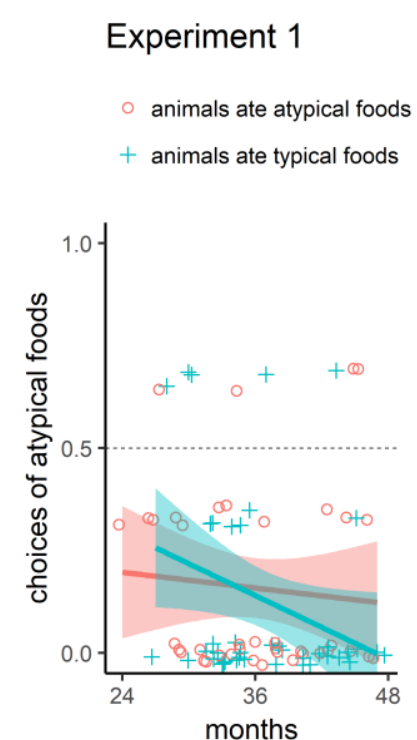

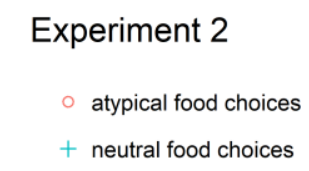

Experiment 3

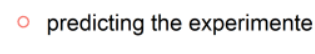

+ child's own response

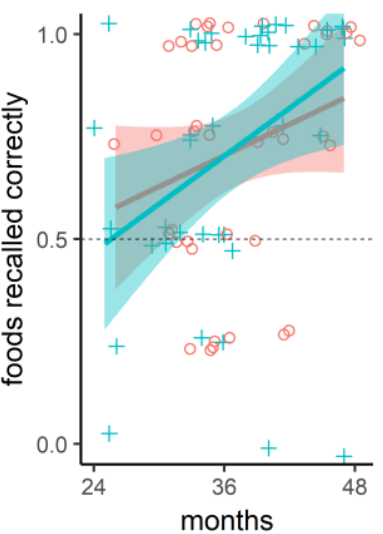

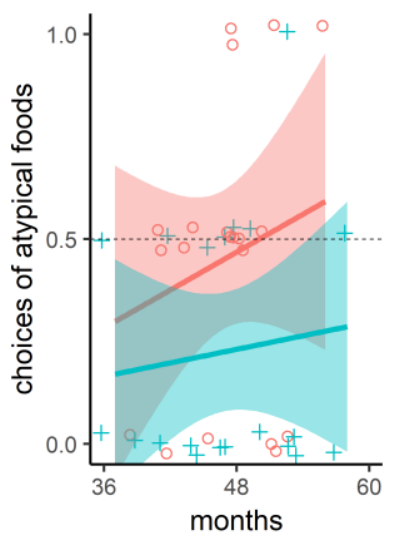

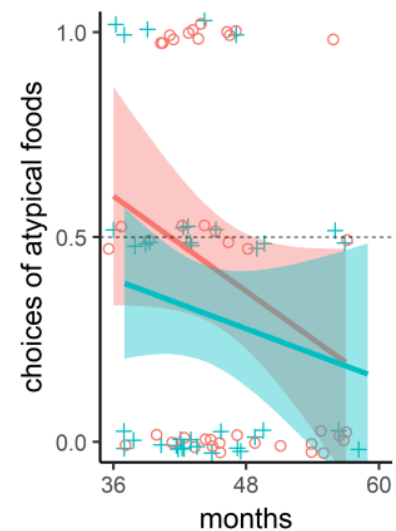

Figure 1. Scatterplots showing children's responses in each experiment. Points are jittered to avoid overplotting and bands show \pm 1 standard error.

These findings suggest that children as young as 2 and 3 show the typicality bias. In the next experiments, we attempted to test whether the bias stems from processing limits.

\section{Experiment 2}

The typicality bias could stem from a failure to remember unusual information in stories. Such memory problems could prevent children from generalizing about the events, leaving them with little reason to choose atypical events for the story. Consistent with this memory account, children sometimes have difficulty remembering information that conflicts with their prior expectations (e.g., Ceci et al., 1981), including information that conflicts with gender stereotypes (e.g., Liben \& Signorella, 1993; Signorella \& Liben, 1984; also see Frawley et al., 2008).

However, this memory account does not readily fit with claims that counter-intuitive information is often especially memorable (Boyer, 2001; see Banerjee et al., 2013 for developmental evidence). A related explanation for the bias is that even if children do remember the events, they might be unwilling to recount them accurately (i.e., because the events are atypical). This would 
also impede children from including atypical events in stories. To examine these possibilities, we tested children's memory for events in a story in which animals ate atypical foods.

\section{Methods}

Participants. We tested 802 - and 3-year-olds $(M=3 ; 1$, range $=2 ; 1-3 ; 11,40$ males $)$. One other child was tested but excluded for not answering any test questions.

Materials and procedure. Children first saw a picture of four animals and were told the animals were hungry. To encourage children to think of the scenarios as parts of a story, the animals appeared in front of a forest background, the story began with "Once upon a time...", and the animals were given names. Children then watched four scenarios in which the animals found and ate food. In each scenario, immediately after children were told which food the animal ate, they were asked a comprehension question to ensure they understood (e.g. "Sammy decides to eat the pear. So which food did Sammy eat?"). Next, children completed four test trials. In each trial, they were again shown slides of each of the animals with both foods and were asked to recall what each animal ate (e.g. "Look here's Sammy again! Do you remember which food Sammy ate?’).

Children completed the experiment in one of two between-subjects conditions. One condition used the same animals and foods as Experiment 1, and each animal ate the atypical food rather than the typical one. The other condition served to provide a baseline measure of children's memory abilities. It was identical to the first condition, except it featured animals that do not typically prefer either food (goat, raccoon, pig, moose).

\section{Results and Discussion}

Figure 1 (second panel) shows the proportion of trials in which children responded correctly to the memory questions. The GEE model revealed no main effect of condition, Wald 
$\chi^{2}(1)=0.05, p=.820$, and no interaction between condition and age, Wald $\chi^{2}(1)=0.35, p=.557$ However, there was a main effect of age, Wald $\chi^{2}(1)=7.37, p=.007$, resulting because memory performance was better in older children than younger ones. To examine whether children's memory performance exceeded chance, we followed-up with one-sample tests, and ran separate tests for 2- and 3-year-olds because of the main effect of age. Performance exceeded chance at both ages: 2 -year-olds, Wald $\chi^{2}(1)=9.47, p=.002 ; 3$-year-olds, Wald $\chi^{2}(1)=20.85, p<.001$.

These findings show that the typicality bias does not result from difficulty remembering the unusual events in the story, and that children are willing to recount unrealistic events. Indeed, because this experiment tested children's memory across four trials, the memory demands were greater than those in the first experiment or any of the later experiments (the other experiments had fewer initial trials in which children saw atypical events). In the next experiment, we tested whether the typicality bias reflects an alternative processing limit.

\section{Experiment 3}

The typicality bias could result from children failing to recognize the pattern of unrealistic events in the story—even though children remember these events, they might not be able to integrate them. Alternatively, children may recognize the pattern of unrealistic events but choose to not continue it.

To test these accounts, this experiment included a condition where children predicted how the experimenter would choose to continue the story. If children overlook the pattern of atypical events in the story, they may continue to show the typicality bias when predicting what the experimenter will say. Conversely, if children recognize the pattern, they might predict that the experimenter will continue to say that the animals will eat atypical foods. Previous research shows that 3-4-year-olds, and even toddlers, can predict that other people's preferences and 
actions will differ from their own (e.g., Ma \& Xu, 2011; Smith et al., 2013). To increase the likelihood that children would recognize the pattern of atypicality, we tested slightly older children, and showed children three unrealistic scenarios (i.e., one more than in Experiment 1).

\section{Methods}

Participants. We tested 403 - and 4-year-olds ( $M=4 ; 3$, range = 3;1-4;10, 19 males $)$. Two other children were tested but excluded for not answering any test questions. In this experiment, and those subsequent, we tested 20 children per age (in years) per between-subject condition, as in these experiments, we were most interested in the comparisons across betweensubjects conditions.

Materials and procedure. Children first saw a picture of five animals and were told the animals were hungry. Children then watched three scenarios in which the monkey, the squirrel, and the rabbit appeared with the same foods as Experiments 1 and 2, and each animal ate the atypical food. The "enriched" version of the script was used, where the animals were given names and the story began with "Once upon a time".

Children then completed two test trials. In each, one of the two remaining animals appeared with a typical food and an atypical food (mouse with cheese and pineapple; dog with a bone and some peas). In one-between subjects condition, children were asked what each animal would eat (e.g. "Mitch decides to eat a food. So, what food will Mitch eat?”). In the other between-subjects conditions, children were instead asked to predict what the experimenter would say (e.g., "Mitch decides to eat a food. So, what food will I say?")

\section{Results and Discussion}

Figure 1 (third panel) shows the proportion of trials in which children chose the atypical foods. The GEE model revealed a main effect of condition, Wald $\chi^{2}(1)=4.62, p=.032$, but no 
main effect of age, Wald $\chi^{2}(1)=1.04, p=.308$, and no interaction, Wald $\chi^{2}(1)=0.12, p=.735$. The main effect of condition resulted because choices of the atypical food were more common when children predicted what the experimenter would say than when they gave their own response. One-sample tests revealed that when giving their own responses, children mostly picked the typical food, Wald $\chi^{2}(1)=10.71, p=.001$. When predicting what the experimenter would say, children did not significantly choose one food over the other, Wald $\chi^{2}(1)=0.40, p=$ .526 .

These findings show that the typicality bias is diminished in 3-4-year-olds when they predict what the experimenter will say. Nonetheless, children's chance-level responding in this condition suggests that they might not have recognized the pattern of unrealistic events in the story. This pattern is similar to what Weisberg et al. (2013), observed in a "desire" control condition in which children saw evidence that the experimenter preferred unrealistic over realistic pictures, but then responded at chance when asked to indicate which of two pictures the experimenter liked better. We were surprised that children could not predict what the experimenter would say, and so we next examined whether another manipulation might help children override the typicality bias.

\section{Experiments $4 A$ and $4 B$}

These studies used the same procedure except Experiment 4A used the enriched version of the script in which animals were given names, and the story began with "Once upon a time..."), whereas Experiment 4B used a script without these elements. The studies examined whether asking children to explain the behaviors of the animals in the initial scenarios would shift them away from the typicality bias. Generating causal explanations is thought to benefit children's induction and generalization (e.g., Legare \& Lombrozo, 2014; Walker et al., 2014), 
and so we anticipated that asking for explanations might prompt children to draw the generalization that animals in the story eat atypical foods. To this end, children in one condition were asked to explain why the animals had eaten the foods, while children in a control condition were asked how the animal ate the food. In this experiment, we also confirmed that children understand that it is unusual for the animals to eat species-atypical foods ("Do squirrels usually eat pears?").

\section{Methods}

Participants. We tested a total of 79 3- and 4-year-olds $(M=3 ; 9$, range $=3 ; 0-4 ; 11,38$ males). One other child was tested but excluded for not answering any test questions. Experiment 4A was run on the first 40 children, who were all tested by one experimenter; Experiment 4B was run on the next 39 children, who were all tested by another experimenter.

Materials and procedure. In both experiments, children first saw a picture of five animals, and were told the animals were hungry. Children then watched three scenarios in which the monkey, the squirrel, and the rabbit appeared with the same foods as in the earlier experiments, and each animal ate the atypical food. Children were asked if each animal usually ate that food (e.g., "Do monkeys usually eat apples?"). Then, children were asked an open-ended question in one of two between-subjects conditions. In the "Why" condition, they were asked why the animal ate that food, and in the "How" condition, they were asked how the animal ate the food (e.g., "Why/How do you think the monkey ate the apple?"). If children did not respond, the experimenter repeated the question before moving on; if children said, "I don't know", the experimenter prompted them by asking "What do you think?" before moving on to the next trial.

Children then completed two test trials. In each, one of the two remaining animals appeared with a typical food and an atypical food (mouse with cheese and pineapple; dog with a 
bone and some peas), and children were asked which food it would eat (e.g. 'Look! Here's a mouse. And look! Here's a pineapple and some cheese. What food will the mouse eat?’)

\section{Results and Discussion}

We first examined children's responses to the questions about whether animals in the three preliminary scenarios usually ate the chosen foods. Denials that animals usually ate the food were more common in older than younger children, Wald $\chi^{2}(1)=11.82, p=.001$. Nonetheless, single-sample tests showed that children at each age denied that the animals typically ate their chosen foods, $p \mathrm{~s}<.001$ (82\% of 3-year-olds' responses and 98\% of 4-yearolds' responses). These responses did not differ across Experiments $4 \mathrm{~A}$ and $4 \mathrm{~B}$, Wald $\chi^{2}(1)=$ $0.02, p=.877$, and experiment also did not interact with age, Wald $\chi^{2}(1)=0.22, p=.642$.

Turning to the test trials, Figure 1 (fourth panel) shows the proportion of trials in which children chose the atypical foods. We entered experiment (4A, 4B) as a factor along with the other factors (i.e., condition, age-in-months). The model revealed no significant effects. There was no main effect of condition, Wald $\chi^{2}(1)=1.31, p=.252$, no main effect of age, Wald $\chi^{2}(1)=$ $0.20, p=.651$, and no main effect of experiment, Wald $\chi^{2}(1)=3.14, p=.076$. There was also no interaction between condition and age, Wald $\chi^{2}(1)=0.14, p=.907$, no interaction between script and condition, Wald $\chi^{2}(1)=0.45, p=.500$, and no three-way interaction between script, condition, and age, Wald $\chi^{2}(1)=0.41, p=.520$. Because the main analysis yielded no significant effects, we followed-up with a single one-sample test that collapsed across all factors. It showed that children mostly chose species-typical foods, Wald $\chi^{2}(1)=8.98, p=.003$.

In designing this experiment, we did not plan on coding children's explanations and we did not fully transcribe them, as previous work suggested that merely being asked to provide an explanation suffices to affect children's reasoning - it benefits performance even when this 
might not be expected based on the content of the explanation children actually provide (Walker et al., 2014). Also, we did not have specific hypotheses about which kinds of explanations might be linked with increased choices of atypical foods. Finally, the content of children's explanations is unlikely to predict these choices, as they were very rare. For example, Figure 1 shows that only one 4-year-old chose atypical in both test trials. It is worth noting though, that a casual examination of the explanations provided suggests that children did attempt to generate meaningful explanations. Although some children could not say why each animal ate atypical foods, other children responded by saying the animal "wanted to" or with other plausible explanations (e.g., "he wants to try something different", "he doesn't see the banana", "it didn't want carrots today").

These findings again suggest that children show a typicality bias for stories. The findings provide no positive evidence that attempting to explain the anomalous story events led to improved generalizations, but responses to the preliminary questions demonstrate that children understood that the foods chosen in the preliminary trials were atypical.

\section{General Discussion}

Children showed a typicality bias for stories. Specifically, children aged 2-4 judged that animals in stories would eat species-typical foods, even though other animals in the stories had eaten foods atypical for their species. These findings suggest that children decide what will happen in a story by drawing on their knowledge of what is typically or normally true. Importantly, these findings are not readily explained by children showing a reality-bias, as the options offered to children were not impossible or fantastic.

Our findings suggest that the typicality bias is present in children as young as age 2. This is substantially earlier than the earliest demonstration of children's related bias to favor realistic 
over unrealistic fiction. Although the bias for realism is well documented in children aged 4 years (Sobel \& Weisberg, 2014; Weisberg et al., 2013) and older (Kibbe et al., 2018), Sobel and Weisberg did not find it in 3-year-olds. Further research would be needed to investigate whether these biases show different patterns of development. Regardless, in demonstrating that even toddlers show the typicality bias, our findings join earlier work (e.g., Keil \& Batterman, 1984; Shtulman \& Carey, 2007) in showing the importance of typicality in children's thinking.

Our findings also suggest that children have difficulty disregarding the typicality bias. Although children accurately remembered atypical story events they had already heard, two manipulations intended to lead them to disregard the bias were largely ineffectual. First, we asked children to predict how the experimenter would continue a story featuring atypical events. Even though these predictions should not depend on children's own preferences, they only predicted that the story would continue with atypical events at chance rates. Second, we asked children to explain atypical events in a story, a manipulation that could have prompted children to notice the pattern of atypical events. But children persisted in judging that further events in the story would be typical.

Although we cannot be entirely sure why these manipulations failed, one explanation is that children may have difficulty noticing patterns of atypical events in stories. If young children do not draw generalizations like animals in this story eat atypical foods, they may default to base judgments on their knowledge of what animals typically eat. Another potential explanation is that the bias arises from limits in children's inhibitory processing. Judging that animals will eat atypical foods could be challenging for the same reason that children find it difficult to say "night" in response to pictures of the sun and to say "day" in response to pictures of the moon (e.g., Gerstadt, Hong, \& Diamond, 1994). In contrast, answering questions about atypical events 
that have already transpired may be easier because these responses are based on memory, not on generating and heeding a counterintuitive rule.

However, previous findings cast doubt on these explanations. Some work shows that young children can sometimes generalize about atypical and even impossible events (e.g., the word-learning condition in Weisberg et al., 2013; also see Van de Vondervoort \& Friedman, 2014). Also, the inhibitory account is undermined by findings showing that children as young as age 2 can generate answers that conflict with their knowledge when reasoning according to counterfactual premises, like 'all fish live in trees' (Dias \& Harris, 1988, 1990; Richards \& Sanderson, 1999). Also, an inhibitory account might predict the typicality bias should have decreased across the age range we examined (e.g., Carlson, 2005), however, it appeared to remain stable across age groups. Regardless, the findings that children have difficulty disregarding the typicality bias suggests that that it has a strong effect on their thinking about fiction.

We close by considering three questions raised by our findings. First, what is the scope of the typicality bias? We contrasted events that would be typical versus atypical in real life. However, the typicality bias might also incorporate children's knowledge of what is typically true in stories. Many things that are common in stories are atypical in children's daily lives or outright impossible. For example, in stories, it is typical for dragons to breath fire and ghosts to haunt houses. If children's notions of typicality encompass what is typically true in stories, the bias might allow children to anticipate that these kinds of characters will show their typical story-book tendencies, even though they are not encountered in children's daily lives. Earlier studies on the reality bias did not speak to this issue because the events they concerned (e.g., teleporting to a store) were atypical in real life and stories alike. 
A second question is how the typicality bias relates to children's reality bias for fiction. As we have discussed, the typicality bias could explain many findings attributed to the reality bias. For instance, children may judge that a story character will walk rather than teleport to a store because teleporting is unfamiliar and atypical (even in stories for children), and not because it is outright impossible. This could lead to the conclusion that the two biases constitute a single bias (i.e., reality could be as a subset of what is typical). However, this conclusion would be undermined if the biases emerge at different ages (a possibility raised above). The idea that they constitute a single bias would also be undermined if the biases can be put in conflict with one another (i.e., this would not be possible if they constitute a single bias). Again, asking children about fantasy characters like dragons and ghosts might provide a way of exploring this possibility, because what is typical for these creatures (in stories at least) is impossible and hence unrealistic.

A final question is whether the typicality bias operates most strongly on certain forms of typicality. Prasada and colleagues (e.g., Prasada \& Dillingham, 2006; Howard, Wagner, Carey, \& Prasada, 2018) distinguish between two senses of typicality: Some typical properties reflect statistical regularities only, whereas others are viewed as having a more principled basis. One indication of this difference is that people take violations of principled regularities more seriously than violations of statistical regularities. Dogs typically wear collars, but people do not think much is wrong if a dog does not have a collar. Dogs also typically have four legs, and people are much more likely to think something is wrong if a dog has fewer legs. Returning to our studies, children may believe that there are principled reasons for why animals eat speciestypical foods, and children might even think that there are principled reasons why princesses and wizards live in their typical dwellings (though this is much more tenuous). It is possible, then, 
that children would be less likely to show the typicality bias, or might be more likely to override the bias, if we focused on features of things that are only statistically typical. 


\section{References}

Banerjee, K., Haque, O. S., \& Spelke, E. S. (2013). Melting lizards and crying mailboxes: Children's preferential recall of minimally counterintuitive concepts. Cognitive Science, 37(7), 1251-1289. https://doi.org/10.1111/cogs.12037

Bowman-Smith, C. K., Shtulman, A., \& Friedman, O. (2019). Distant lands make for distant possibilities: Children view improbable events as more possible in far-away locations. Developmental Psychology, 55(4), 722-728. https://doi.org/10.1037/dev0000661

Boyer, P. (2001). Religion explained: The evolutionary origins of religious thought. Basic Books.

Carlson, S. M. (2005). Developmentally sensitive measures of executive function in preschool children. Developmental Neuropsychology, 28(2), 595-616. https://doi.org/10.1207/s15326942dn2802_3

Ceci, S. J., Caves, R. D., \& Howe, M. J. (1981). Children's long-term memory for information that is incongruous with their prior knowledge. British Journal of Psychology, 72(4), 443-450. https://doi.org/10.1111/j.2044-8295.1981.tb01772.x

Corriveau, K. H., Kim, A. L., Schwalen, C. E., \& Harris, P. L. (2009). Abraham Lincoln and Harry Potter: Children's differentiation between historical and fantasy characters. Cognition, 113(2), 213-225. https://doi.org/10.1016/j.cognition.2009.08.007

Frawley, T. J. (2008). Gender schema and prejudicial recall: How children misremember, fabricate, and distort gendered picture book information. Journal of Research in Childhood Education, 22(3), 291-303. https://doi.org/10.1080/02568540809594628 
Gerstadt, C. L., Hong, Y. J., \& Diamond, A. (1994). The relationship between cognition and action: Performance of children 3 1/2-7 years old on a Stroop-like day-night test. Cognition, 53(2), 129-153. https://doi.org/10.1016/0010-0277(94)90068-X

Goldstein, T. R., \& Alperson, K. (2019). Dancing bears and talking toasters: A content analysis of supernatural elements in children's media. Psychology of Popular Media Culture. Advance online publication. https://doi.org/10.1037/ppm0000222

Goulding, B. W., \& Friedman, O. (in press). Children's beliefs about possibility differ across dreams, stories, and reality. Child Development. https://doi.org/10.1111/cdev.13386

Haward, P., Wagner, L., Carey, S., \& Prasada, S. (2018). The development of principled connections and kind representations. Cognition, 176, 255-268. https://doi.org/10.1016/j.cognition.2018.02.001

Kavanaugh, R. D., \& Harris, P. L. (1994). Imagining the outcome of pretend transformations: Assessing the competence of normal children and children with autism. Developmental Psychology, 30(6), 847-854. https://doi.org/10.1037/0012-1649.30.6.847

Kibbe, M. M., Kreisky, M., \& Weisberg, D. S. (2018). Young children distinguish between different unrealistic fictional genres. Psychology of Aesthetics, Creativity, and the Arts, 12(2), 228-235. https://doi.org/10.1037/aca0000115

Lane, J. D., Ronfard, S., \& El-Sherif, D. (2018). The influence of first-hand testimony and hearsay on children's belief in the improbable. Child Development, 89(4), 1133-1140. https://doi.org/10.1111/cdev.12815

Lane, J. D., Ronfard, S., Francioli, S. P., \& Harris, P. L. (2016). Children's imagination and belief: Prone to flights of fancy or grounded in reality? Cognition, 152, 127-140. https://doi.org/10.1016/j.cognition.2016.03.022 
Legare, C. H., \& Lombrozo, T. (2014). Selective effects of explanation on learning during early childhood. Journal of Experimental Child Psychology, 126, 198212. https://doi.org/10.1016/j.jecp.2014.03.001

Leslie, A. M. (1994). Pretending and believing: Issues in the theory of ToMM. Cognition, 50(13), 211-238. https://doi.org/10.1016/0010-0277(94)90029-9

Li, H., Boguszewski, K., \& Lillard, A. S. (2015). Can that really happen? Children's knowledge about the reality status of fantastical events in television. Journal of Experimental Child Psychology, 139, 99-114. https://doi.org/10.1016/j.jecp.2015.05.007

Liben, L. S., \& Signorella, M. L. (1993). Gender-schematic processing in children: The role of initial interpretations of stimuli. Developmental Psychology, 29(1), 141149. https://doi.org/10.1037/0012-1649.29.1.141

Keil, F. C., \& Batterman, N. (1984). A characteristic-to-defining shift in the development of word meaning. Journal of Verbal Learning and Verbal Behavior, 23(2), 221-236. https://doi.org/10.1016/S0022-5371(84)90148-8

Ma, L., \& Xu, F. (2011). Young children's use of statistical sampling evidence to infer the subjectivity of preferences. Cognition, 120(3), $403-411$. https://doi.org/10.1016/j.cognition.2011.02.003

Prasada, S., \& Dillingham, E. M. (2006). Principled and statistical connections in common sense conception. Cognition, 99(1), 73-112. https://doi.org/10.1016/j.cognition.2005.01.003

Richards, C. A., \& Sanderson, J. A. (1999). The role of imagination in facilitating deductive reasoning in 2-, 3-and 4-year-olds. Cognition, 72(2), B1-B9. https://doi.org/10.1016/S0010-0277(99)00037-2 
Shtulman, A. (2009). The development of possibility judgment within and across domains. Cognitive Development, 24(3), 293-309. https://doi.org/10.1016/j.cogdev.2008.12.006

Shtulman, A., \& Carey, S. (2007). Improbable or impossible? How children reason about the possibility of extraordinary events. Child Development, 78(3), 1015-1032. https://doi.org/10.1111/j.1467-8624.2007.01047.x

Shtulman, A., \& Phillips, J. (2018). Differentiating "could" from "should": Developmental changes in modal cognition. Journal of Experimental Child Psychology, 165, 161-182. https://doi.org/10.1016/j.jecp.2017.05.012

Signorella, M. L., \& Liben, L. S. (1984). Recall and reconstruction of gender-related pictures: Effects of attitude, task difficulty, and age. Child Development, 55(2), 393405. https://doi.org/10.2307/1129951

Smith, C. E., Blake, P. R., \& Harris, P. L. (2013). I should but I won't: Why young children endorse norms of fair sharing but do not follow them. PloS ONE, 8(3), Article e59510. https://doi.org/10.1371/journal.pone.0059510

Sobel, D. M., \& Weisberg, D. S. (2014). Tell me a story: How children's developing domain knowledge affects their story construction. Journal of Cognition and Development, 15(3), 465-478. https://doi.org/10.1080/15248372.2012.736111

Van de Vondervoort, J. W., \& Friedman, O. (2014). Preschoolers can infer general rules governing fantastical events in fiction. Developmental Psychology, 50(5), 15941599. https://doi.org/10.1037/a0035717

Van de Vondervoort, J. W., \& Friedman, O. (2017). Young children protest and correct pretense that contradicts their general knowledge. Cognitive Development, 43, 182189. https://doi.org/10.1016/j.cogdev.2017.05.002 
Walker, C. M., Lombrozo, T., Legare, C. H., \& Gopnik, A. (2014). Explaining prompts children to privilege inductively rich properties. Cognition, 133(2), 343357. https://doi.org/10.1016/j.cognition.2014.07.008

Weisberg, D. S. (2013). Distinguishing imagination from reality. In M. Taylor (Ed.), The Oxford Handbook of the Development of Imagination (pp. 75-93). Oxford University Press. https://doi.org/10.1093/oxfordhb/9780195395761.013.0006

Weisberg, D. S., \& Sobel, D. M. (2012). Young children discriminate improbable from impossible events in fiction. Cognitive Development, 27(1), 9098. https://doi.org/10.1016/j.cogdev.2011.08.001

Weisberg, D. S., Sobel, D. M., Goodstein, J., \& Bloom, P. (2013). Young children are realityprone when thinking about stories. Journal of Cognition and Culture, 13(3-4), 383407. https://doi.org/10.1163/15685373-12342100

Woolley, J. D., \& Cox, V. (2007). Development of beliefs about storybook reality. Developmental Science, 10(5), 681-693. https://doi.org/10.1111/j.1467$\underline{7687.2007 .00612 . x}$ 